\title{
CARACTERIZAÇÃO MORFOLÓGICA DE CALOS DE Eucalyptus urophylla S. T. Blake SOB CONCENTRAÇÕES DE BORO E CÁLCIO
}

\author{
Raquel Trevizam¹, Gilvano Ebling Brondani², Felipe Uassurê Nery³, Antonio Natal Gonçalves ${ }^{4}$, \\ Marcilio de Almeida ${ }^{5}$
}

(recebido: 12 de dezembro de 2009; aceito: 25 de fevereiro de 2011)

\begin{abstract}
RESUMO: Objetivou-se avaliar o efeito de diferentes concentrações de B e Ca nas respostas morfológicas e tamanho de calos de Eucalyptus urophylla, obtidos a partir da porção mediana de hipocótilos excisados de plântulas germinadas in vitro. As estruturas calogênicas foram cultivadas por períodos de 21 e 31 dias, sendo mantidas no meio N7 modificado nas concentrações de B $(0,25$, 50,100 e $200 \mu \mathrm{M}$ de $\left.\mathrm{H}_{3} \mathrm{BO}_{3}\right)$ e $\mathrm{Ca}\left(0 ; 3,75 ; 7,5 ; 11,25\right.$ e $15 \mathrm{mM}$ de $\left.\mathrm{CaCl}_{2} .2 \mathrm{H}_{2} \mathrm{O}\right)$. Os calos foram analisados quanto ao tamanho, presença de raízes, friabilidade, aspecto gelatinoso, presença de estruturas globulares na superfície e presença de pigmentos. De maneira geral, o menor tempo de cultivo (21 dias) possibilitou melhor desenvolvimento das estruturas calogênicas. A combinação de $50 \mu \mathrm{M}$ de $\mathrm{H}_{3} \mathrm{BO}_{3}$ e $7,5 \mathrm{mM}$ de $\mathrm{CaCl}_{2} .2 \mathrm{H}_{2} \mathrm{O}$ aos 21 dias, e de $100 \mu \mathrm{M}$ de $\mathrm{H}_{3} \mathrm{BO}_{3}$ e $1,13 \mathrm{mM} \mathrm{CaCl} .2 \mathrm{H}_{2} \mathrm{O}$ aos 31 dias, promoveram os melhores resultados. A rizogênese respondeu de forma variável às concentrações de $\mathrm{B}$ e Ca. A omissão simultânea de $\mathrm{B}$ e Ca inibiu a rizogênese, causou a desestruturação dos calos, e favoreceu a formação de estruturas globulares e friáveis, com a ocorrência de antocianina. Concentrações elevadas de cálcio promoveram a indução de raízes nos calos.
\end{abstract}

Palavras-chave: Meio de cultura, nutrição mineral, cultivo in vitro, cultura de tecidos, rizogênese.

\section{MORPHOLOGICAL CHARACTERIZATION OF CALLI OF Eucalyptus urophylla S. T. Blake SUBJECTED TO CONCENTRATIONS OF BORON AND CALCIUM}

\begin{abstract}
This study aimed to evaluate the effect of B and Ca concentrations on morphological responses and size of calli in Eucalyptus urophylla. Calli were obtained from the mid portion of hypocotyls removed from in vitro germinated seedlings. The callus structures were cultivated for 21 and 31 days, being kept in a modified N7 medium with concentrations of B (0; 25; 50; 100 and $\left.200 \mu \mathrm{M} \mathrm{H}_{3} \mathrm{BO}_{3}\right)$ and $\mathrm{Ca}\left(0 ; 3.75 ; 7.5 ; 11.25\right.$ and $\left.15 \mathrm{mM} \mathrm{CaCl} .2 \mathrm{H}_{2} \mathrm{O}\right)$. Size of calli, presence of roots, friability, viscosity, presence of globular structures on the surface and presence of pigments were analyzed. Overall, the shorter culture period (21 days) allowed better development of callus structures. The combination of $50 \mu \mathrm{M} \mathrm{H}_{3} \mathrm{BO}_{3}$ with $7.5 \mathrm{mM} \mathrm{CaCl} .2 \mathrm{H}_{2} \mathrm{O}$ at 21 days, and 100 $\mu \mathrm{M} \mathrm{H}_{3} \mathrm{BO}_{3}$ with $1.13 \mathrm{mM} \mathrm{CaCl} .2 \mathrm{H}_{2} \mathrm{O}$ at 31 days, provided best results. Rhizogenesis responded differently according to $\mathrm{B}$ and Ca concentrations. Simultaneous omission of $B$ and $C a$ inhibited the rhizogenesis, causing disruption of the callus, favored formation of globular and friable structures, with presence of anthocyanin. High concentrations of calcium promoted root induction in calli.
\end{abstract}

Key words: Culture medium, mineral nutrition, in vitro cultivation, tissue culture, rhizogenesis.

\section{INTRODUÇÃO}

A morfologia vegetal consiste na investigação da forma ou da estrutura da planta, podendo ser interpretada de acordo com o formato externo (HAJARI et al., 2006; NEHRA et al., 2005). A importância deste aspecto em estudos com organismos vegetais deve-se às relações com que este parâmetro se apresenta quando relacionado à fisiologia vegetal. Quando um explante é inoculado in vitro, diversas respostas são esperadas e a determinação de fatores químicos, morfológicos e fisiológicos dos tecidos de plantas doadoras têm sido fundamentais (GLOCKE et al., 2006).

Diferentes respostas morfogenéticas são observadas no cultivo in vitro de espécies vegetais em meios suplementados com reguladores de crescimento, sendo que as respostas também estão ligadas ao balanço nutricional do meio de cultura (GEORGE, 1993; GUNTER et al., 2007; MUSSIO; RUSIG, 2009). Dessa forma, a nutrição mineral pode influenciar a morfologia vegetal de várias maneiras, podendo se destacar a atuação do cálcio (Ca) e do boro (B).

\footnotetext{
${ }^{1}$ Engenheira Florestal, Dra . em Recursos Florestais - Programa de Pós-Graduação em Recursos Florestais - Escola Superior de Agricultura "Luiz de Queiroz"/ESALQ - Universidade de São Paulo/USP - Avenida Pádua Dias, 11 - Cx. P. 09 - 13418-900 - Piracicaba, SP - trevisan@esalq.usp.br ${ }^{2}$ Engenheiro Florestal, Doutorando em Recursos Florestais, Bolsista FAPESP - Programa de Pós-Graduação em Recursos Florestais - Escola Superior de Agricultura "Luiz de Queiroz"-Universidade de São Paulo/USP-Avenida Pádua Dias, 11-Cx. P. 09-13418-900-Piracicaba, SP-brondani@esalq.usp.br ${ }^{3}$ Engenheiro Agrônomo, Mestrando em Recursos Florestais - Programa de Pós-Graduação em Recursos Florestais - Escola Superior de Agricultura “Luiz de Queiroz”/ESALQ - Universidade de São Paulo/USP - Avenida Pádua Dias, 11 - Cx. P. 09 - 13418-900 - Piracicaba, SP - funery@usp.br ${ }^{4}$ Engenheiro Agrônomo, Professor Dr. em Agronomia - Departamento de Ciências Florestais - Escola Superior de Agricultura "Luiz de Queiroz"/ESALQ Universidade de São Paulo/USP - Avenida Pádua Dias, 11 - Cx. P. 09 - 13418-900 - Piracicaba, SP - natalgon@esalq.usp.br ${ }^{5}$ Biólogo, Professor Dr. em Botânica - Departamento de Botânica - Escola Superior de Agricultura "Luiz de Queiroz"/ESALQ - Universidade de São Paulo/USP - Avenida Pádua Dias, 11 - Cx. P. 09 - 13418-900 - Piracicaba, SP - malmeida@esalq.usp.br
} 
O Ca se destaca como constituinte da lamela média (integridade da parede celular). A deficiência de Ca pode afetar particularmente os pontos de crescimento da raiz, com o surgimento de núcleos poliplóides, células binucleadas, núcleos conscritos, divisões amitóticas, podendo cessar o desenvolvimento e até mesmo ocorrer escurecimento e morte do tecido vegetal. Já o B participa de complexos como manitol, ácido polimanurônico e outros constituintes das paredes celulares, estando envolvido no alongamento e na divisão celular. Sintomas de deficiência aparecem em regiões meristemáticas, promovendo acúmulo de compostos fenólicos, necrose de tecidos e dificultando a diferenciação e divisão celular (EPSTEIN; BLOOM, 2004; MALAVOLTA, 2006; TANAKA; FUJIWARA, 2008).

Considerando-se a importância dessas caracterizações estruturais ocasionadas por modificações nutricionais em meio de cultura, objetivou-se, com o presente trabalho, avaliar as alterações morfológicas apresentadas por calos de Eucalyptus urophylla cultivados in vitro em dois períodos distintos de cultivo em função de concentrações de boro e cálcio.

\section{MATERIAL E MÉTODOS}

\subsection{Obtenção dos explantes}

Utilizaram-se sementes de Eucalyptus urophylla S.T. Blake fornecidas pelo Instituto de Pesquisas e Estudos Florestais (IPEF), as quais foram catalogadas como T8A32, lote NA416 e coletadas da população base de Anhembi-SP. As sementes foram lavadas em água corrente por cinco vezes, sendo em seguida transferidas para álcool etílico $100 \%$ por três segundos. Posteriormente, as sementes foram imersas em solução de hipoclorito de sódio $(\mathrm{NaOCl})$ a $70 \%$ $(\mathrm{v} / \mathrm{v})$ contendo Tween $20(0,05 \% \mathrm{v} / \mathrm{v})$, onde permaneceram sob agitação por 20 minutos. Em seguida, as sementes foram submetidas a três lavagens sequenciais em água deionizada e esterilizada, sendo posteriormente inoculadas em meio nutritivo N7 (Tabela 1) destinado à germinação.

\subsection{Aplicação dos tratamentos}

Os hipocótilos foram excisados na porção mediana com comprimento de $5 \mathrm{~mm}$. Estes explantes foram mantidos por 21 dias em meio N7, o qual foi suplementado com $5 \mathrm{mg} \mathrm{L}^{-1}$ de Picloram e $1 \mathrm{mg} \mathrm{L}^{-1}$ de caseína hidrolisada, a fim de induzir a calogênese. Em seguida, foram cultivados, por dois períodos distintos, 21 e 31 dias, sendo os calos transferidos para meio de cultura N7 modificado em relação às concentrações de ácido bórico $\left(\mathrm{H}_{3} \mathrm{BO}_{3}\right)$ e cloreto de cálcio $\left(\mathrm{CaCl}_{2} \cdot 2 \mathrm{H}_{2} \mathrm{O}\right)$, explicitados na Tabela 2 .
Tabela 1 - Composição básica do meio de cultura utilizado para o cultivo in vitro de calos de E. urophylla.

Table 1 - Basic composition of a culture medium used for in vitro cultivation of E. urophylla calli.

\begin{tabular}{|c|c|}
\hline Componente & Concentração \\
\hline Macronutriente & $\left(\mathrm{mg} \mathrm{L}^{-1}\right)$ \\
\hline$\left(\mathrm{NH}_{4}\right)_{2} \mathrm{SO}_{4}$ & 463,0 \\
\hline $\mathrm{KNO}_{3}$ & $2.830,0$ \\
\hline $\mathrm{MgSO}_{4} \cdot 7 \mathrm{H}_{2} \mathrm{O}$ & 185,0 \\
\hline $\mathrm{KH}_{2} \mathrm{PO}_{4}$ & 399,5 \\
\hline $\mathrm{CaCl}_{2} \cdot 2 \mathrm{H}_{2} \mathrm{O}$ & 166,0 \\
\hline Micronutriente & $\left(\mathrm{mg} \mathrm{L}^{-1}\right)$ \\
\hline $\mathrm{FeSO}_{4} \cdot 7 \mathrm{H}_{2} \mathrm{O}$ & 50,0 \\
\hline $\mathrm{Na}_{2}$-EDTA. $2 \mathrm{H}_{2} \mathrm{O}$ & 67,0 \\
\hline $\mathrm{H}_{3} \mathrm{BO}_{3}$ & 6,2 \\
\hline $\mathrm{ZnSO}_{4} \cdot 7 \mathrm{H}_{2} \mathrm{O}$ & 8,6 \\
\hline $\mathrm{MnSO}_{4} \cdot \mathrm{H}_{2} \mathrm{O}$ & 16,9 \\
\hline $\mathrm{KI}$ & 0,83 \\
\hline $\mathrm{Na}_{2} \mathrm{MoO}_{4} \cdot 2 \mathrm{H}_{2} \mathrm{O}$ & 0,25 \\
\hline $\mathrm{CuSO}_{4} \cdot 5 \mathrm{H}_{2} \mathrm{O}$ & 0,025 \\
\hline $\mathrm{CoCl}_{2} \cdot 6 \mathrm{H}_{2} \mathrm{O}$ & 0,025 \\
\hline Vitaminas e aminoácidos & $\left(\mathrm{mg} \mathrm{L}^{-1}\right)$ \\
\hline Ácido nicotínico & 0,5 \\
\hline Tiamina-HCl & 0,1 \\
\hline Piridoxina- $\mathrm{HCl}$ & 0,5 \\
\hline Glicina & 2,0 \\
\hline Fonte de carbono & $\left(\mathrm{mg} \mathrm{L}^{-1}\right)$ \\
\hline Mio-inositol & 100 \\
\hline Sacarose & 20.000 \\
\hline
\end{tabular}

Fonte: Simola (1985), modificado.

Source: Simola (1985), modified.

\subsection{Preparo do meio de cultura}

Os meios de cultura foram ajustados para $\mathrm{pH}$ de 5,8 com $\mathrm{HCl}$ ou $\mathrm{NaOH}(1 \mathrm{M}$ ou $0,1 \mathrm{M})$, autoclavados à temperatura de $121^{\circ} \mathrm{C}\left(\approx 1,0 \mathrm{kgf} \mathrm{cm}^{-2}\right)$, durante 20 minutos, e distribuídos em placa de petri contendo $10 \mathrm{ml}$ do meio de cultura. $\mathrm{O}$ meio de cultura foi suplementado com $6 \mathrm{~g} \mathrm{~L}^{-1}$ de ágar.

\subsection{Condições de cultivo}

Os explantes foram cultivados, em sala de crescimento, com temperatura mantida a $25 \pm 2{ }^{\circ} \mathrm{C}$, fotoperíodo de 16 horas e luminosidade de $42 \mu \mathrm{mol} \mathrm{m}^{-2} \mathrm{~s}^{-1}$, a partir de lâmpadas fluorescentes branca-fria. 
Tabela 2 - Tratamentos utilizados para o cultivo in vitro de calos de E. urophylla.

Table 2 - Treatments used for in vitro cultivation of E. urophylla calli.

\begin{tabular}{|c|c|c|c|}
\hline \multicolumn{2}{|c|}{ Tempo } & \multirow{2}{*}{$\frac{\mathrm{H}_{3} \mathrm{BO}_{3}}{(\mu \mathrm{M})}$} & \multirow{2}{*}{$\frac{\mathrm{CaCl}_{2} \cdot 2 \mathrm{H}_{2} \mathrm{O}}{(\mathrm{mM})}$} \\
\hline 21 dias & 31 dias & & \\
\hline $\mathrm{T} 1$ & $\mathrm{~T} 27$ & 0 & 0,00 \\
\hline $\mathrm{T} 2$ & $\mathrm{~T} 28$ & 0 & 3,75 \\
\hline T3 & T29 & 0 & 7,50 \\
\hline $\mathrm{T} 4$ & $\mathrm{~T} 30$ & 0 & 11,25 \\
\hline T5 & T31 & 0 & 15,00 \\
\hline T6 & T32 & 25 & 0,00 \\
\hline $\mathrm{T} 7$ & T33 & 25 & 3,75 \\
\hline T8 & T34 & 25 & 7,50 \\
\hline T9 & $\mathrm{T} 35$ & 25 & 11,25 \\
\hline $\mathrm{T} 10$ & T36 & 25 & 15,00 \\
\hline T11 & T37 & 50 & 0,00 \\
\hline T12 & T38 & 50 & 3,75 \\
\hline T13 & T39 & 50 & 7,50 \\
\hline $\mathrm{T} 14$ & $\mathrm{~T} 40$ & 50 & 11,25 \\
\hline $\mathrm{T} 15$ & $\mathrm{~T} 41$ & 50 & 15,00 \\
\hline T16 & $\mathrm{T} 42$ & 100 & 0,00 \\
\hline T17 & $\mathrm{T} 43$ & 100 & 3,75 \\
\hline T18 & $\mathrm{T} 44$ & 100 & 7,50 \\
\hline T19 & $\mathrm{T} 45$ & 100 & 11,25 \\
\hline $\mathrm{T} 20$ & $\mathrm{~T} 46$ & 100 & 15,00 \\
\hline $\mathrm{T} 21$ & $\mathrm{~T} 47$ & 200 & 0,00 \\
\hline $\mathrm{T} 22$ & $\mathrm{~T} 48$ & 200 & 3,75 \\
\hline $\mathrm{T} 23$ & T49 & 200 & 7,50 \\
\hline $\mathrm{T} 24$ & $\mathrm{~T} 50$ & 200 & 11,25 \\
\hline $\mathrm{T} 25$ & $\mathrm{~T} 51$ & 200 & 15,00 \\
\hline $\mathrm{T} 26$ & T52 & $100^{*}$ & $1,13^{*}$ \\
\hline
\end{tabular}

*meio de cultura N7 padrão (Tabela 1).

*standard N7 culture medium.

\subsection{Avaliação das análises morfológicas}

As análises morfológicas externas foram efetuadas aos 21 e aos 31 dias. Os calos foram analisados quanto ao tamanho, presença de raízes, friabilidade, aspecto gelatinoso, presença de estruturas globulares na superfície do calo e de pigmentos (antocianinas). A friabilidade e as diferenças organográficas foram avaliadas de forma visual, à medida que se destacavam dentro de um tratamento específico.

\subsection{Delineamento experimental}

Utilizou-se o delineamento inteiramente casualizado em arranjo fatorial $(5 \times 5)$, com parcelas subdivididas no tempo (21 e 31 dias), sendo os fatores constituídos por concentrações de $\mathrm{H}_{3} \mathrm{BO}_{3}$ e $\mathrm{CaCl}_{2} .2 \mathrm{H}_{2} \mathrm{O}$ (Tabela 2). Para tanto, utilizaram-se cinco repetições contendo 20 calos, totalizando 100 calos. Os dados foram submetidos a análise de variância a 5\% de probabilidade de erro.

\section{RESULTADOS E DISCUSSÃO}

\subsection{Tamanho dos calos}

Pela análise de variância correspondente ao tamanho médio de calo, constatou-se interação $(\mathrm{P}<0,05)$ entre as concentrações de cálcio e boro com o tempo de cultivo in vitro. De maneira geral, os calos mensurados aos 21 dias de cultivo in vitro apresentaram maiores diferenças estruturais quando comparados aos calos mantidos por 31 dias em meio de cultura (Figura 1).

Foi possível constatar, através da análise dos resultados grafados na Figura 1, que o cultivo prolongado dos calos ocasionou uma redução dos processos de desenvolvimento. Após 21 dias de cultivo in vitro notou-se que os calos formados iniciaram um processo de oxidação, com consequente redução do crescimento e enraizamento, com mínima observação rizogênica aos 31 dias.

A exposição de materiais vegetais cultivados in vitro, por períodos determinados em meio de cultura pode interferir em seu desenvolvimento (LEITZKE et al., 2009), sendo que com a perda de água das células para o meio de cultura ou ainda, os processos de autólise caracterizariam efeito de proteção da planta em situação de estresse. $\mathrm{O}$ esgotamento mineral do meio de cultura pode ter induzido os calos a uma deficiência crônica de um ou mais nutrientes essenciais ao desenvolvimento e metabolismo celular, o que poderia ter retardado o processo de crescimento e desenvolvimento radicular.

Diversos fatores como o genótipo e o meio de cultura são relatados como responsáveis por afetar a morfogênese in vitro e o desenvolvimento das plantas (GEORGE, 1993; NEHRA et al., 2005). Borgatto et al. (2002) também verificaram influência do tempo de cultivo in vitro de Chrysanthemum morifolium, principalmente em meios com baixas concentrações de cálcio, o que afetou negativamente a calogênese e o crescimento dos calos. 


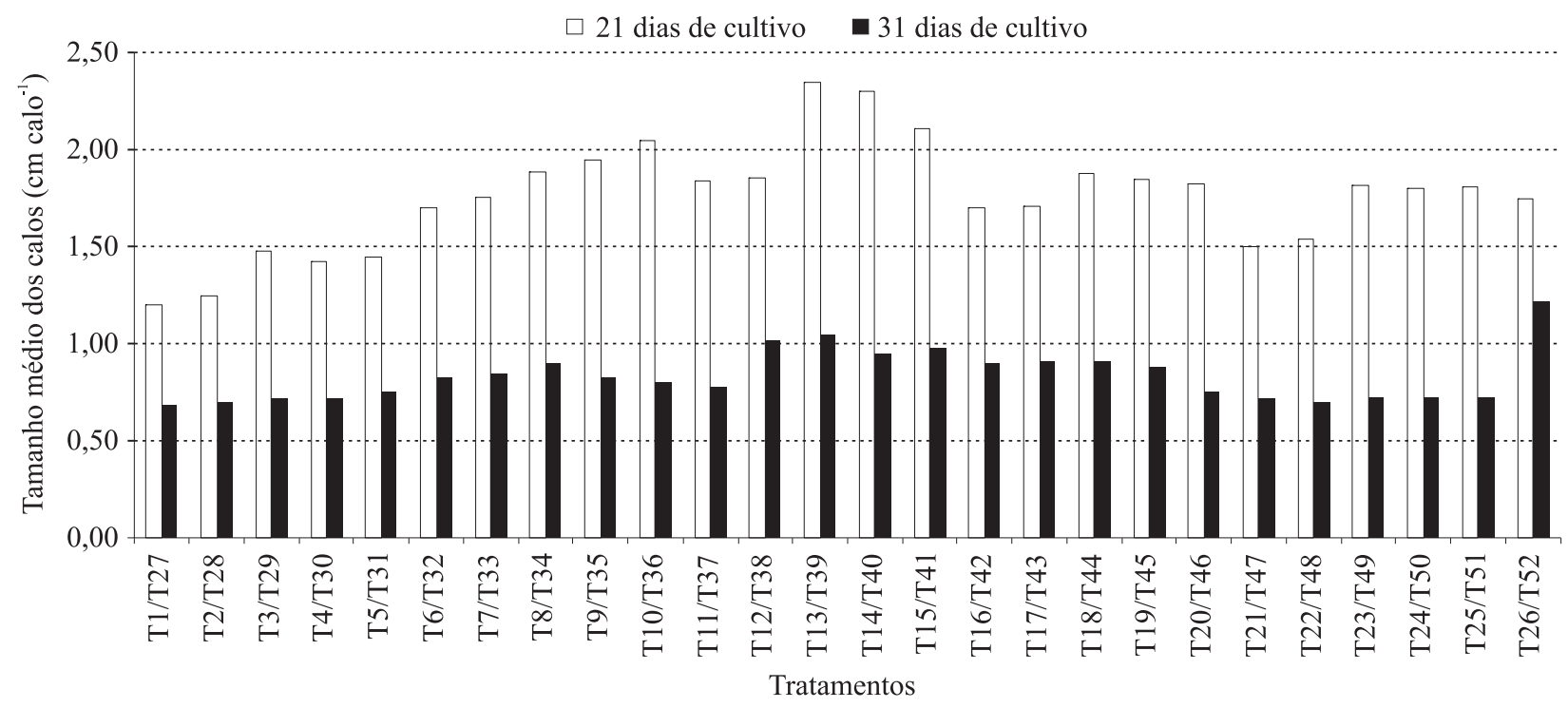

Figura 1 - Tamanho médio de calos de E. urophylla cultivados in vitro em meio N7 modificado com concentrações de boro e cálcio aos 21 e 31 dias.

Figure 1 - Average size of E. urophylla calli cultivated in vitro in a modified $N 7$ medium with various boron and calcium concentrations at 21 and 31 days.

As análises referentes ao tamanho dos calos cultivados in vitro por 21 dias indicaram que a concentração com $50 \mu \mathrm{M}$ de boro e 7,5 $\mathrm{mM}$ de cálcio foram as mais eficientes (T13), enquanto que, em períodos mais longos de cultivo (31 dias), destacou-se o meio padrão (T52).

$\mathrm{O}$ fato de culturas mais prolongadas se adaptarem melhor ao meio padrão (T52) pode ser devido à existência de uma disponibilidade nutricional satisfatória, capaz de manter o crescimento de calos desta espécie, mesmo em situações adversas de cultivo.

Independente da concentração de cálcio empregada, ao se utilizar $50 \mu \mathrm{M}$ de boro no meio de cultura (T11, T12, T13, T14, T15, T37, T38, T39, T40 e T41), os calos responderam positivamente a estas concentrações (Figura 1), apresentando aumento no tamanho dos calos. Trevizam (2001), testando doses de boro em cultivos in vitro de E. urophylla, também relatou desenvolvimento regular dos calos nesta mesma concentração de boro, ou seja, $50 \mu \mathrm{M}$. Dessa forma, podemos inferir que diante das condições testadas, essa concentração poderia ser indicada como a mais eficiente no desenvolvimento das estruturas calogênicas.

Em ambos os períodos de cultivo, verificou-se que os calos cultivados em meio de cultura sem cálcio e boro (T1 e T27) apresentaram desenvolvimento reduzido das estruturas, quando comparados com tratamentos em que se combinou a ausência do macronutriente com concentrações crescentes e diferentes de boro.

Esses efeitos podem denotar a interferência do micronutriente no crescimento vegetal e na sua capacidade de remediar as deficiências do cálcio. De acordo com Malavolta (2006), a quantidade e disponibilidade de um dos nutrientes (cálcio ou boro) podem interferir na distribuição e também no requerimento do outro nutriente para alcançar um índice de crescimento ótimo da planta, destacando a importância desses elementos para o crescimento das espécies.

\subsection{Presença de raízes}

Os calos apresentaram células de aspecto meristemático, porém arranjadas de forma distinta, sendo que, aos 31 dias de cultivo, essas estruturas mostraramse organizadas em estratos com células alongadas, com núcleos aparentes e diferenciação de sistema vascular sem a formação convencional de raízes (Figura 2a-d).

Por meio das análises histológicas, verificou-se a indução de raízes com diferenciação de sistema vascular na maioria dos tratamentos (Figura 2a e 2b), excetuando-se em T1, T13 e T26 que não apresentaram o desenvolvimento do órgão. Já na avaliação de calos cultivados in vitro por 31 dias (Figura 2b), observaram-se raízes apenas em T30, T31, T35, T36, T45, T49, T50 e T51.

Cerne, Lavras, v. 17, n. 2, p. 215-222, abr./jun. 2011 


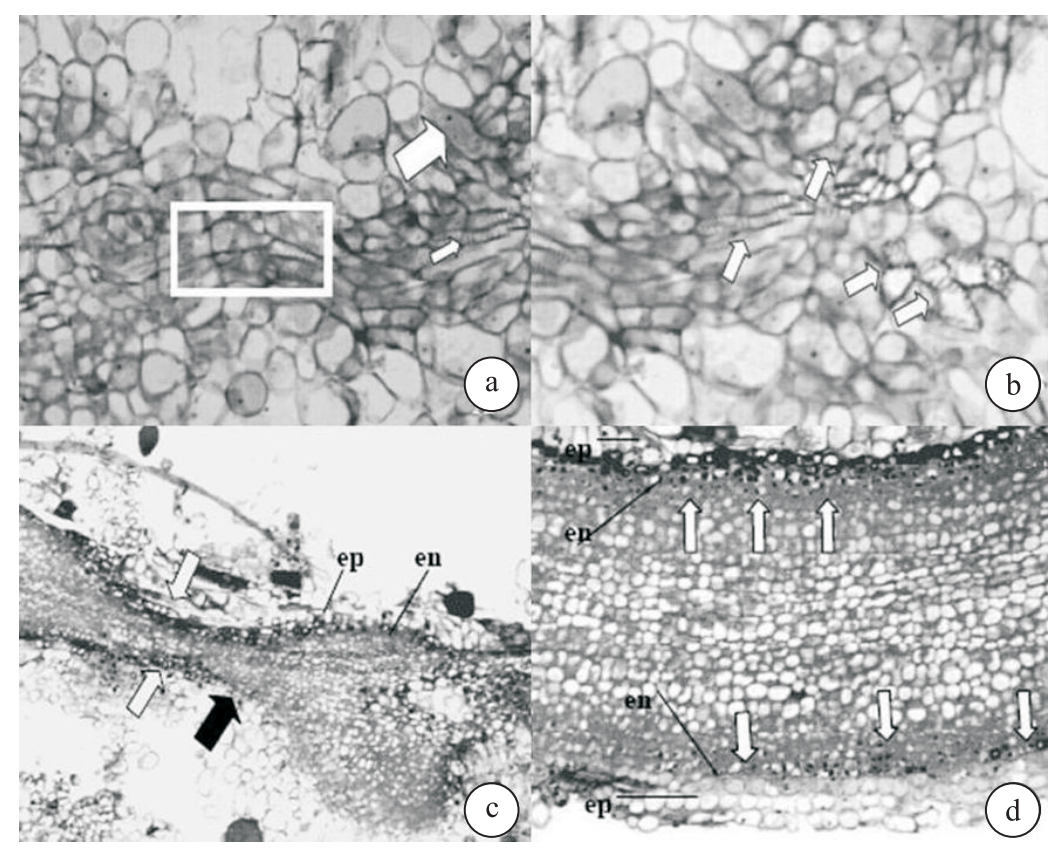

Figura 2 - Presença de raízes em calos de E. urophylla cultivados in vitro em meio N7 modificado com concentrações de boro e cálcio (T36) aos 31 dias. a) Detalhe: células com baixa relação núcleo citoplasmáticas com formas alongadas, evidenciando diferenciação de sistema fundamental; Seta maior: núcleos proeminentes com indicação de divisão celular; Seta menor: diferenciação e organização de sistema vascular. b) Setas: detalhe de elementos vasculares do xilema formados isoladamente e aleatoriamente nos calos. c) Corte longitudinal em raiz. Seta branca: raiz apresentando conformação desestruturada com células coradas na endoderme; Seta escura: ausência de células epidérmicas. d) Corte longitudinal em raiz. Setas: detalhe da região com espessamento de células indicando maior diferenciação. ep - epiderme, en - endoderme.

Figure 2 - Root presence in calli of E. urophylla, cultivated in vitro in a modified N7 medium with concentrations of boron and calcium (T36) at 31 days. a) Detailed area: cells with a low nucleus/cytoplasm ratio, with elongated forms, evidencing a differentiated ground system; Big arrow: prominent nuclei with indication of cell division; Small arrow: differentiation and organization of vascular system. b) Arrows: detailed vascular elements of xylem formed separately and randomly in calli. c) Lengthwise cut of root. White arrow: root presenting destructured conformation with colored cells in the endodermis; Dark arrow: absence of epidermal cells. d) Lengthwise cut of root. Arrows: detailed area with cell thickening indicating greater differentiation. ep - epidermis, en - endodermis.

Observou-se também que a conformação das células epidérmicas foi irregular e descontínua. Logo abaixo da epiderme, observou-se a presença da endoderme, a qual se caracterizou pela presença de células arredondadas contornando o cilindro vascular na maior parte da estrutura. Esse espessamento poderia indicar a formação de tecido de sustentação com fibras esclerenquimáticas (Figuras 2c e 2d).

Diante dos resultados obtidos, constatou-se que as limitações do meio de cultura foram determinantes para que os calos só respondessem à rizogênese, de forma mais eficiente, sob concentrações mais elevadas de cálcio, ou seja, em concentrações superiores a 7,5 mM. Em tratamentos com omissão total de boro e cálcio (T1 e T27), não se registrou a formação de raízes (Figura 3).

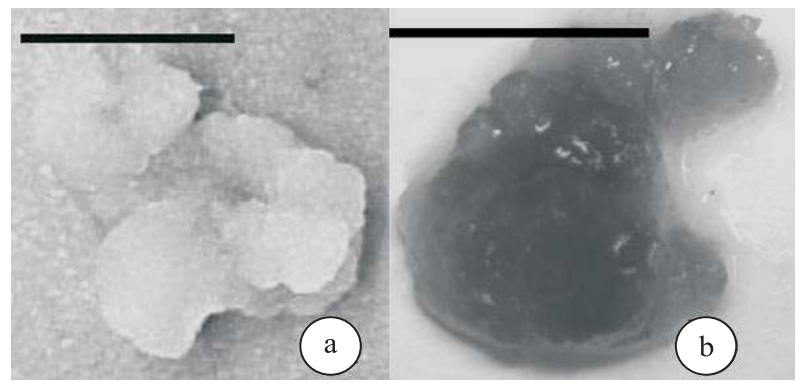

Figura 3 - Estruturas calogênicas E. urophylla com aspecto gelatinoso. a) Calo aos 21 dias (T1); b) Calo aos 31 dias (T27). Escala: $0,5 \mathrm{~cm}$.

Figure 3 - Callus structures of E. urophylla with a viscous aspect. a) Callus at 21 days (T1); b) Callus at 31 days (T27). Scale: $0.5 \mathrm{~cm}$. 
O efeito da omissão de boro em raízes é conhecido e controverso. Recentemente, Villa et al. (2009) comprovaram que a adição de ácido bórico ao meio de cultura in vitro proporcionou maior número de folhas e comprimento de raízes do porta-enxerto de videira 'Kobber' (Vitis sp.).

A quantidade e a disponibilidade de cada um dos nutrientes podem afetar a distribuição e o requerimento do outro nutriente para que a planta expresse um índice de crescimento global (MALAVOLTA, 2006). Desta forma, pode-se supor que o B e Ca atuam de maneira sinérgica em processos organogênicos enquanto que as ausências conjuntas de ambos os nutrientes podem ter interferido na rizogênese in vitro de E. urophylla.

\subsection{Aspecto gelatinoso}

Foi verificada a ocorrência de calos com aspecto gelatinoso quando cultivados in vitro com concentrações distintas de boro e cálcio aos 21 e aos 31 dias (Figura 3a e $3 b)$.

Observou-se que, independente das concentrações de cálcio utilizadas, os calos cultivados com omissão de boro apresentaram aspectos gelatinosos nos tratamentos T1, T2, T3, T4, T27, T28 e T29. Da mesma forma, o tratamento T21 (com omissão de cálcio e concentração tóxica de boro) mostrou a mesma desestruturação na conformação dos calos (Figura 3a e 3b).

Diversos autores confirmam a atuação do macro e do micronutriente na formação e na gênese da parede e da membrana celular (EPSTEIN; BLOOM, 2004; MALAVOLTA, 2006), fato que confirmaria a desestruturação das formações calogênicas quando estes nutrientes são omitidos ou apresentam concentrações inadequadas para o desenvolvimento dos calos. Trevizam (2005), ao estudar a interferência do boro e do cálcio em calos de E. urophylla, evidenciou interferência semelhante ao omitir estes nutrientes do meio de cultura, resultando em pronunciada desagregação celular.

\subsection{Estruturas globulares e friabilidade}

Evidenciou-se $\mathrm{o}$ aspecto de estruturas globulares na superfície de calos cultivados in vitro com concentrações distintas de boro e cálcio aos 21 e 31 dias (Figura 4a e 4b).

Aos 31 dias de cultivo, estruturas globulares foram visualizadas em quase todos os tratamentos, exceto em T32, T33, T37, T41, T45 ao T52. Ao passo que, aos 21 dias, estas estruturas apresentaram aspectos mais brilhantes e ocorreram apenas nos tratamentos T8, T9, T10, T13 e T14.

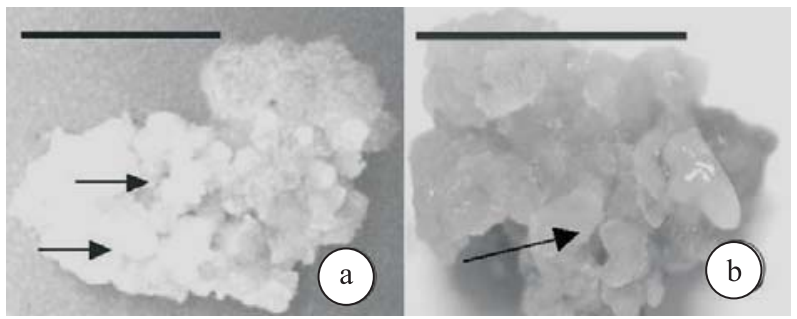

Figura 4 - Estruturas calogênicas de E. urophylla com aspecto globular. Setas: a) Calo aos 21 dias (T13); b) Calo aos 31 dias (T34). Escala: 0,5 cm.

Figure 4 - Callus structures of E. urophylla with a globular aspect. Arrows: a) Callus at 21 days (T13); b) Callus at 31 days (T34). Scale: $0.5 \mathrm{~cm}$.

Da mesma forma que a presença de estruturas globulares, a friabilidade dos calos foi um aspecto comum nas culturas avaliadas aos 21 dias (T6, T7, T11, T16, T18, T24 e T25), enquanto que, para os cultivos de 31 dias, a formação de estruturas friáveis foi comprometida pela oxidação, apresentando-se apenas nos tratamentos: T28 ao T31, T38, T39, T41 e T46 (Figura 5a e 5b).

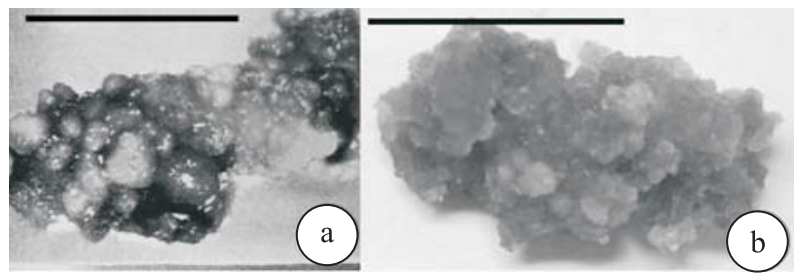

Figura 5 - Estruturas calogênicas de E. urophylla com aspecto friável. a) Calos aos 21 dias (T16); b) Calos aos 31 dias (T31). Escala: $0,5 \mathrm{~cm}$.

Figure 5 - Callus structures of E. urophylla with a friable aspect. a) Callus at 21 days (T16); b) Callus at 31 days (T31). Scale: $0.5 \mathrm{~cm}$.

As formas globulares associadas à superfície dos calos podem caracterizar a presença de organogênese e/ou embriogênese somática. Contudo, essas afirmações apenas podem ser comprovadas através de análises da morfologia interna (TREVIZAM, 2005).

Muitos são os fatores que influenciam o comportamento do explante no meio de cultura, incluindo o órgão que serve como fonte de tecido, a idade fisiológica e ontogenética do órgão, o tamanho do explante e, acima de tudo, a qualidade da planta doadora (GEORGE, 1993). 


\subsection{Presença de pigmentos}

De acordo com os dados da morfologia externa apresentados na Figura 6, verificou-se a presença de dois pigmentos distintos nos calos de E. urophylla, sendo um caracterizado pela cor marrom, definida pela oxidação fenólica e outro com coloração vermelha em consequência da presença de antocianina.

A oxidação (coloração marrom) mostrou relação com a redução do desenvolvimento das estruturas cultivadas por 21 dias nos tratamentos T1 ao T9 e T17 ao T25. No período de análise posterior (31 dias), a oxidação dos calos foi bastante evidenciada em todos os tratamentos, porém no T51 a oxidação causou os maiores danos aos calos (Figura 6a).

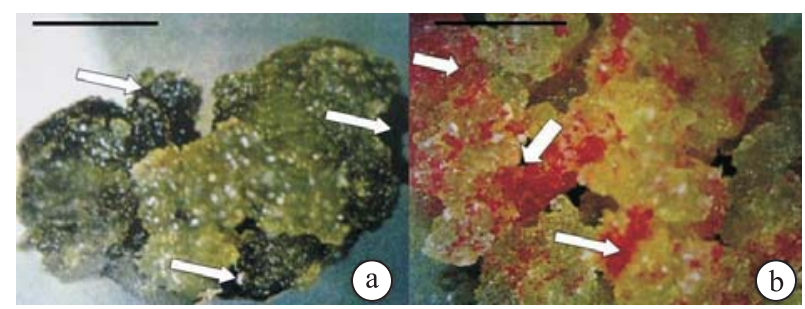

Figura 6 - Presença de pigmentos em calos de E. urophylla cultivados in vitro com concentrações distintas de boro e cálcio. Setas: a) Presença de oxidação aos 31 dias (T51); b) Presença de antocianinas em calos aos 31 dias (T51). Escala: 0,5 cm.

Figure 6 - Presence of pigments in E. urophylla calli cultivated in vitro with various concentrations of boron and calcium. Arrows: a) Presence of oxidation at 31 days (T51); b) Presence of anthocyanins in calli at 31 days (T51). Scale: $0.5 \mathrm{~cm}$.

Independentemente das concentrações de cálcio empregadas, o meio de cultura com $50 \mu \mathrm{M}$ de boro aos 21 dias foi o único a não caracterizar o surgimento do pigmento marrom. Em muitos casos, a deficiência de boro associa-se ao escurecimento de tecidos foliares, sendo este escurecimento consequência provável de acúmulo de fenóis e da atividade da polifenol-oxidase (PPO) de acordo com Cakmak et al. (1995). As quinonas produzidas pela PPO são polimerizadas e geram pigmentos marrons, em que o acúmulo de quantidades substanciais de quinonas em espécies de plantas sensíveis a deficiência de boro tem sido considerado como a maior causa de danos e suspensão do crescimento celular em diversas espécies vegetais (LEE; ARONOFF, 1967). Dessa forma, a produção de fenóis apresenta-se como uma resposta ao desequilíbrio do meio de cultura sendo que o cálcio, isoladamente, não remedia esse acúmulo nas células.
Diferentemente da coloração marrom, os tons de vermelho estão relacionados a promoção do desenvolvimento em tamanho dos calos (Figura 6b). Dessa forma, o tratamento T13 apresentou calos com coloração vermelha marcante e, ao mesmo tempo, apresentou os maiores tamanhos médios. Outros tratamentos também apresentaram o pigmento (T1, T5, T7, T10, T11, T14, T15, T17, T19 e T23), no entanto, a intensidade da coloração foi inferior à do tratamento T13. Em calos cultivados por 31 dias, a antocianina foi visualiza somente em T40 (Figura 6b).

A cultura in vitro de células de plantas pode acumular grande variedade de metabólicos secundários como polifenóis, alcalóides, esteróides e antocianinas, que tendem a se perder em períodos prolongados de cultivo (GEORGE, 1993; NEHRA et al., 2005). A presença de antocianinas já foi relatada na organogenêse (SUBBAIAH; MINOCHA, 1990) e na embriogênese somática (ARRUDA et al., 2000; TREVIZAM, 2001) de Eucalyptus, o que está de acordo com o observado no presente trabalho.

\section{CONCLUSÕES}

As concentrações distintas de boro e cálcio e o tempo de cultivo interferiram no tamanho e na morfologia externa dos calos de Eucalyptus urophylla cultivados in vitro.

Concentrações mais elevadas de cálcio promoveram a indução de raízes nos calos.

A omissão simultânea de $\mathrm{B}$ e Ca inibiu a rizogênese, causou a desestruturação dos calos, e favoreceu a formação de estruturas globulares e friáveis, com a ocorrência de pigmentos característicos como antocianina.

\section{AGRADECIMENTOS}

À FAPESP e à CAPES pelo apoio financeiro.

\section{REFERÊNCIAS}

ARRUDA, S. C. C.; SOUZA, G. M.; ALMEIDA, M.; GONÇALVES, A. N. Anatomical and biochemical characterization of the calcium effect on Eucalyptus urophylla callus morphogenesis in vitro. Plant Cell, Organ and Tissue Culture, Netherlands, v. 63, n. 2, p. 142-154, 2000.

BORGATTO, F.; DIAS, C. T. S.; AMARAL, A. F. C.; MELO, M. Calcium, potassium and magnesium treatment of Chrysanthemum morifolium cv. "Bi Time" and callogenesis in vitro. Scientia Agricola, Piracicaba, v. 59, n. 4, p. 689-693, 2002.

Cerne, Lavras, v. 17, n. 2, p. 215-222, abr./jun. 2011 
CAKMAK, I.; KURZ, H.; MARSCHNER, H. Short-term effects of boron germanium and high light intensity on membrane permeability in boron deficient leaves of sunflower. Physiologia Plantarum, Sweden, v. 59, p. 11-18, 1995.

EPSTEIN, E.; BLOOM, A. J. Nutrição mineral de plantas: princípios e perspectivas. Londrina: Planta, 2004. 403 p.

GEORGE, E. F. Plant propagation by tissue culture. 2. ed. Edington: Exegetics, 1993. v. 1, 574 p.

GLOCKE, P.; DELAPORTE, K.; COLLINS, G.; SEDGLEY, M. Micropropagation of juvenile tissue of Eucalyptus erythronema x Eucalyptus stricklandii cv. 'Urrbrae Gem'. In Vitro Cellular \& Developmental Biology - Plant, Berlin, v. 42, n. 2, p. 139-143, 2006.

GUNTER, E. A.; POPEYKO, O. V.; OVODOV, Y. U. Modification of polysaccharides from callus culture of Silene vulgaris (M.) G. using carbohydrases in vitro. Biochemistry, Moscow, v. 72, n. 9, p. 1008-1015, 2007.

HAJARI, E.; WATT, M. P.; MYCOCK, D. J.; McALISTER, B. Plant regeneration from induced callus of improved Eucalyptus clones. South African Journal of Botany, Grahamstown, v. 72, n. 2, p. 195-201, 2006.

LEE, S.; ARONOFF, S. Boron in plants: a biochemical role. Science, Washington, n. 158, p. 798-799, 1967.

LEITZKE, L. N.; DAMIANI, C. R.; SCHUCH, M. W. Meio de cultura, concentração de AIB e tempo de cultivo no enraizamento in vitro de amoreira-preta e framboesa. Revista Brasileira de Fruticultura, Jaboticabal, v. 31, n. 2, p. 582587, 2009.

MALAVOLTA, E. Manual de nutrição mineral de plantas. São Paulo: Agronômica Ceres, 2006. v. 1, 638 p.

MUSSIO, I.; RUSIG, A. M. Morphogenetic responses from protoplasts and tissue culture of Laminaria digitata (Linnaeus) J. V. Lamouroux (Laminariales, Phaeophyta): callus and thalloid-like structures regeneration. Journal of Applied Phycology, Netherlands, v. 21, n. 2, p. 255-264, 2009.

NEHRA, N. S.; BECWAR, M. R.; ROTTMANN, W. H.; PEARSON, L.; CHOWDHURY, K.; CHANG, S.; WILDE, H. D.; KODRZYCKI, R. J.; ZHANG, C.; GAUSE, K. C.; PARKS, D. W.; HINCHEE, M. A. Forest biotechnology: innovative methods, emerging opportunities. In Vitro Cellular \& Developmental Biology - Plant, Berlin, v. 41, n. 6, p. 701-717, 2005.

SIMOLA, L. K. Propagation of plantets from leaf callus of Betula pendula F. purpurea. Scientia Horticulturae, Maryland Heights, v. 26, p. 77-85, 1985.

SUBBAIAH, M. M.; MINOCHA, S. C. Shoot regeneration from stem and leaf callus of Eucalyptus tereticornis. Plant Cell Reports, Berlin, v. 9, p. 370-373, 1990.

TANAKA, M.; FUJIWARA, T. Physiological roles and transport mechanisms of boron: perspectives from plants. Pflügers Archiv - European Journal of Physiology, Berlin, v. 456, n. 4, p. 671-677, 2008.

TREVIZAM, R. Análises histológicas e bioquímicas em calos de Eucalyptus urophylla S.T. Blake cultivados in vitro sob interação nutricional de boro e cálcio. 2005. 150 p. Tese (Doutorado em Recursos Florestais) - Escola Superior de Agricultura “Luiz de Queiroz”, Piracicaba, 2005.

TREVIZAM, R. Atuação de concentrações de boro na morfogênese de Eucalyptus urophylla cultivados in vitro. 2001. 65 p. Dissertação (Mestrado em Recursos Florestais) Escola Superior de Agricultura "Luiz de Queiroz", Piracicaba, 2001.

VILLA, F.; PASQUAL, M.; ASSIS, F. A.; ASSIS, G. A.; ZÁRRAGA, D. Z. A. Micropropagação de duas espécies frutíferas, em meio de cultura DSD1, modificado com fontes de boro e zinco. Ciência e Agrotecnologia, Lavras, v. 33, n. 2, p. 468-472, mar./abr. 2009. 